\title{
ASSESSMENT OF THE EFFECT OF PANRETINAL PHOTOCOAGULATION (PRP) ON MACULAR THICKNESS IN EYES WITH PROLIFERATIVE DIABETIC RETINOPATHY (PDR) WITHOUT CLINICALLY SIGNIFICANT MACULAR EDEMA
}

\author{
By
}

\section{Mostafa Saad Sayed Ahmed, Adel Abd El-Rahman Osman and Ehab Abd El-Sameea Al-Sheikh}

Department of Ophthalmology, Faculty of Medicine, Al Azhar University, Cairo, Egypt

Corresponding author: Mostafa Saad Sayed Ahmed,

Phone No.: +201008325778, E-mail: mostafa.saad.oph@gmail.com

\begin{abstract}
Background: Proliferative diabetic retinopathy (PDR) is the most advanced stage of DR. It significantly increases the risk for progressive vision loss, and without intervention, approximately one half of eyes ultimately experience severe vision loss.

Although PRP is the gold standard treatment of PDR by reducing moderate visual loss by $50 \%$ in treatment groups, it also caused significant macular edema, which is recognized as the most common cause of decreased visual acuity in diabetic eyes. Optical Coherent Tomography (OCT) helps us studying these macular edema and its characteristics.

Objective: To investigate the changes in macular thickness and morphology after panretinal photocoagulation (PRP) in eyes with proliferative diabetic retinopathy (PDR) and without clinically significant macular edema.

Patients and Methods: This study enrolled 20 eyes of 15 patients with early proliferative diabetic retinopathy (PDR) without any clinically significant macular edema. Panretinal photocoagulation was applied 3 sessions, one week apart. Fundus fluorescein angiography and OCT were carried out for all patients before PRP. Baseline and post PRP visual acuity and central foveal thickness were evaluated after 3 months.

Results: The mean patient age was 59.00 \pm 9.93 years (range, 33-72 years). Fifteen of the 20 eyes (75\%) had stable or improved vision, while 5 eyes $(25 \%)$ had worsened by 3 months following PRP. Mean preoperative vision was $0.50 \pm 0.1$ decimal fraction, and although worsened at 3 months $0.48 \pm 0.15$ decimal fraction, this was statistically insignificant $(\mathrm{P}=0.453)$. Mean pre- PRP central foveal thickness was $253.05 \pm 18.53 \mu \mathrm{m}$ (ranging from $227-281 \mu$ ), increased significantly to $281.45 \pm 28.71 \mu \mathrm{m}$ (ranging from $240-344 \mu$ ) at 3 months' follow-up $(\mathrm{P}<0.001)$. Three months after PRP, 15 eyes developed complications. The most common abnormality was cystoid edema seen in 6 eyes (30\%), followed by diffuse macular edema in 4 eyes $(20 \%)$, posterior vitreous detachment (PVD) in 2 eyes (10\%), neuro sensory detachment in two eyes (10\%), and epiretinal membrane (ERM) in one eye $(5 \%)$.

Conclusion: Panretinal photocoagulation is safe, effective in treating and preserving vision in proliferative diabetic retinopathy (PDR), although causing temporary drop in vision and changes in macular morphology/thickness.
\end{abstract}

Keywords: Proliferative diabetic retinopathy, panretinal photocoagulation, optical coherent tomography, macular morphology, foveal thickness. 


\section{INTRODUCTION}

Diabetic retinopathy (DR) is the most common blinding microvascular complication of diabetes mellitus and its prevalence is expected to rise significantly over the next 15 years. The worldwide prevalence of diabetes was $6.4 \%$ in year 2010 and the expected prevalence is $7.7 \%$ by the end of year 2030. Two main reasons for visual loss in diabetic patients are diabetic maculopathy and complications associated with proliferative diabetic retinopathy (Shaw, 2010 and Nentwich \& Ulbig, 2015).

The gold standard treatment for PDR is panretinal laser photocoagulation (PRP) which is required to be performed soon after detection of retinal neovascularization (Chandra et al., 2018).

The mechanism of PRP is to convert the ischemic peripheral retina to anoxic state, thus eliminating the ischemic drive for retinal neovascularization and reducing the intra vitreal VEGF levels (Evans et al., 2014).

The visual and clinical outcome of patients after PRP is dependent upon the surface area of retina over which the laser is applied. Although laser PRP reduces the risk of visual loss in patients with PDR, it may be associated with complications such as visual field loss, macular edema and serious retinal detachment. The incidence of macular edema after PRP has been found in $25 \%$ - $43 \%$ of the eyes and it is considered to be secondary to retinal inflammation and increased vascular permeability that is triggered by laser PRP (Mukhtar et al., 2016).
Optical coherence tomography (OCT) is an imaging modality that currently helps in both the quantitative and qualitative study of macular edema and its characteristics. Although fluorescein angiography is typically used to assess vascular leakage qualitatively in patients with macular edema, assessment of actual macular thickening correlates better with loss of visual acuity. Traditional methods of evaluating macular thickening, including slit-lamp examination and stereo fundus photography, are relatively insensitive to small changes in retinal thickness (Wu et al., 2012).

OCT has proved to be a sensitive tool for detecting subtle cystoid macular edema and subretinal fluid, which may be early and severe manifestations of macular edema and not visualized on clinical or angiographic analysis (Pournaras et al., 2012).

This study was undertaken to investigate the clinical and tomographic correlations between visual changes and macular morphology in patients undergoing PRP for PDR patients.

\section{PATIENTS AND METHODS}

Twenty eyes of 15 dia $\neg$ betic patients, with proliferative diabetic retinopathy (PDR) without clinically significant macular edema attending our retina clinic, were included in our study. The study was approved by our institutional review and ethics board of Al - Azhar University.

History taking from patients included age, sex, previous ocular problems or systemic health problems and family history were recorded. 
All patients underwent a complete ophthalmic examination including assessment of best corrected visual acuity using a Snellen's chart, anterior segment examination by slit-lamp biomicroscopy, intraocular pressure measurement with applanation tonometry, and fundus examination by slit-lamp biomicroscopy and indirect ophthalmoscopy. Fundus fluorescein angiography and OCT were carried out for all patients before PRP. Fluorescein angiography was done to rule out macular ischemia and to confirm early PDR. Cirrus OCT (Carl Zeiss Meditec, Dublin, CA, USA) was done before and 3 months after PRP.

\section{Inclusion criteria:}

Patients with PDR without clinically significant macular edema. Early PDR was identified by the presence of new vessels on one-third of the disc diameter without any preretinal subhyaloid or vitreous hemorrhage- or new vessels elsewhere in the retina.

\section{Exclusion criteria:}

Eyes with clinically significant macular edema, along with patients who had had cataract surgery and/or focal laser treatment or pervious PRP. The presence of corneal opacity, significant cataract, uveitis, glaucoma, aphakia, and poor visual acuity due to any other cause were also excluded.

Procedure: PRP was done with standard parameters using $532 \mathrm{~nm}$ frequencydoubled neodymium-doped yttrium aluminum garnet (Nd-YAG) solid-state pattern scan laser (vitra monospot 532nm, quantel medical) in addition to use a Super Quad 160 contact lens (laser spot magnification of 2.0; Volk Optical Inc., Mentor, $\mathrm{OH})$.

PRP was done in 3 sessions, with a one-week interval between successive sessions.

PRP was placed from just outside the vascular arcades to the peripheral retina, with care taken to prevent laser burns from encroaching within 2 disc diameters (DD) temporal to fovea or $1 \mathrm{DD}$ nasal to the optic disc. The Nd-YAG was used with a retinal spot size $200-300 \mu \mathrm{m}$ and intensity of $200 \mathrm{~mW}$ to $700 \mathrm{~mW}$. The burn intensity was titrated until a graywhite opacity was achieved. The duration of applications was 0.1 second, and the total number of spots was $\sim 1800-2250$.

Follow up: Patients were followed up by clinical examination, visual acuity and OCT after 3 months.

\section{Statistical analysis:}

Recorded data were analyzed using the statistical package for social sciences, version 20.0 (SPSS Inc., Chicago, Illinois, USA). Quantitative data were expressed as mean \pm standard deviation (SD). Qualitative data were expressed as frequency and percentage.

$\mathrm{P}-$ Value $<0.05$ was considered significant . 


\section{RESULTS}

A total of 20 eyes fulfilling the inclusion criteria for this prospective clinical study were included .Ten patients $(66.7 \%)$ were females and five $(33.3 \%)$ were males with a mean age of $59.00 \pm 9.93$ years (range, 33-72 years), with 8 patients $(53.3 \%)$ older than 60 , and seven younger $(46.7 \%)$. Diabetic eyes were 11 right eyes (55\%) and 9 left eyes $(45 \%)$.

Fifteen of the 20 eyes $(75 \%)$ had stable or improved vision, while 5 eyes $(25 \%)$ had worsened by 3 months following PRP. Gender, duration of diabetes, and initial visual acuity were not significant influencing factors with respect to final visual outcome. Mean preoperative vision was $0.50 \pm 0.1$ decimal fraction, and although worsened at 3 months $0.48 \pm 0.15$ decimal fraction, this was statistically insignificant $(\mathrm{P}=0.453$, Figure 1).
Mean preoperative central subfoveal thickness was $253.05 \pm 18.53 \mu \mathrm{m}$ (ranging from $227-281 \mu$ ), increased to $281.45 \pm$ $28.71 \mu \mathrm{m}$ (ranging from $240-334 \mu$ ) at 3 months' follow-up after PRP (Figure 2). Central subfoveal thickness significantly increased at 3 months' follow-up ( $<$ 0.001).

Three months after PRP 15 eyes developed complications. The most common abnormality was cystoid edema seen in 6 eyes $(30 \%)$, followed by diffuse macular edema in 4 eyes (20\%), Posterior vitreous Detachment (PVD) in 2 eyes $(10 \%)$, neuro sensory detachment in two eyes (10\%), and epiretinal membrane (ERM)in one eye (5\%) (Table 1).

PRP total laser burn (shots) was ranged from 1800-2250 with mean $2021.00 \pm$ 174.77 and the power was ranged from $450-650 \mathrm{~mW}$ with mean $540 \pm 61.98 \mathrm{~mW}$ (Table 2).

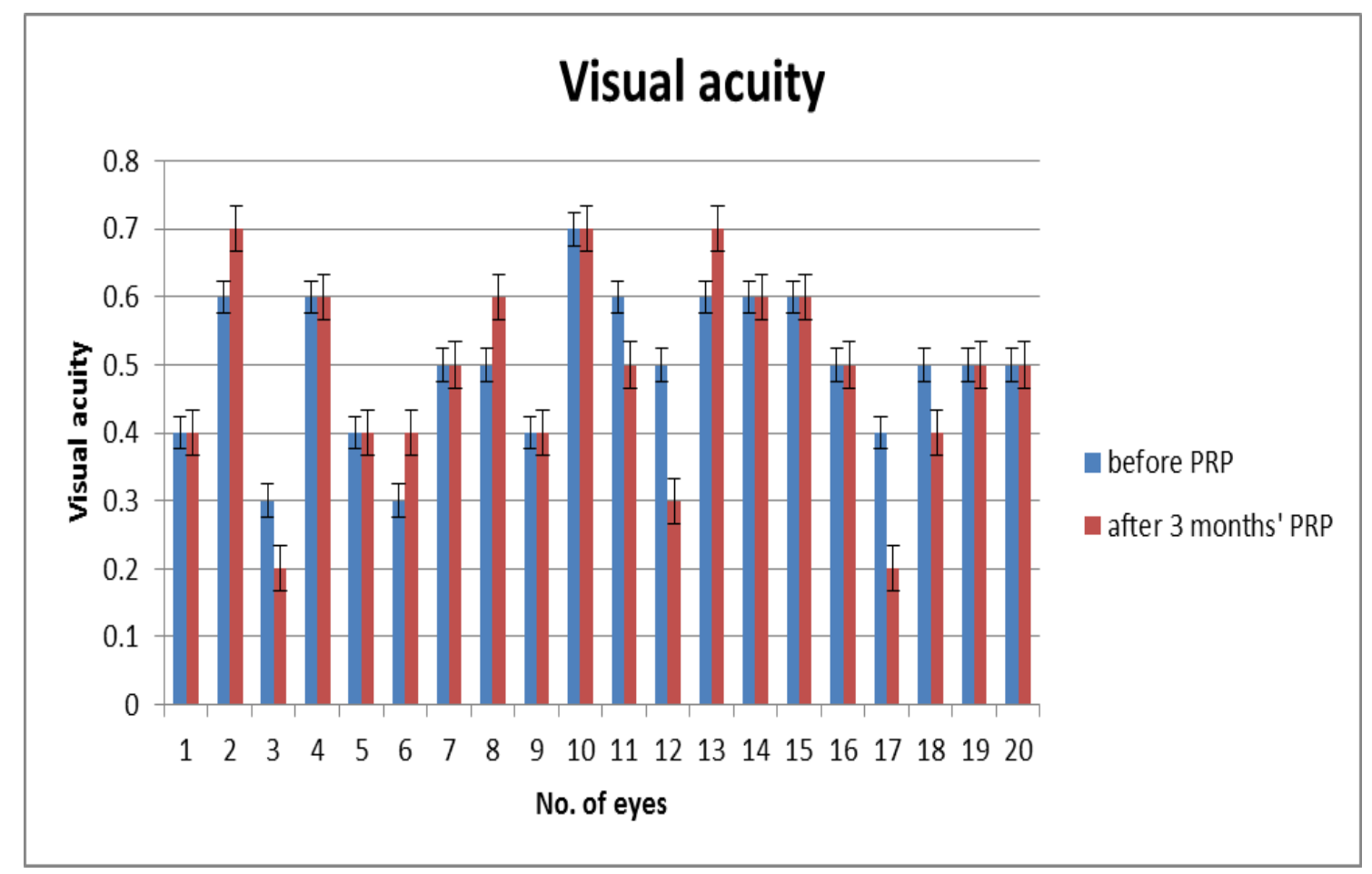

Fig. (1): Comparison between before and after 3 months' PRP according to visual acuity 


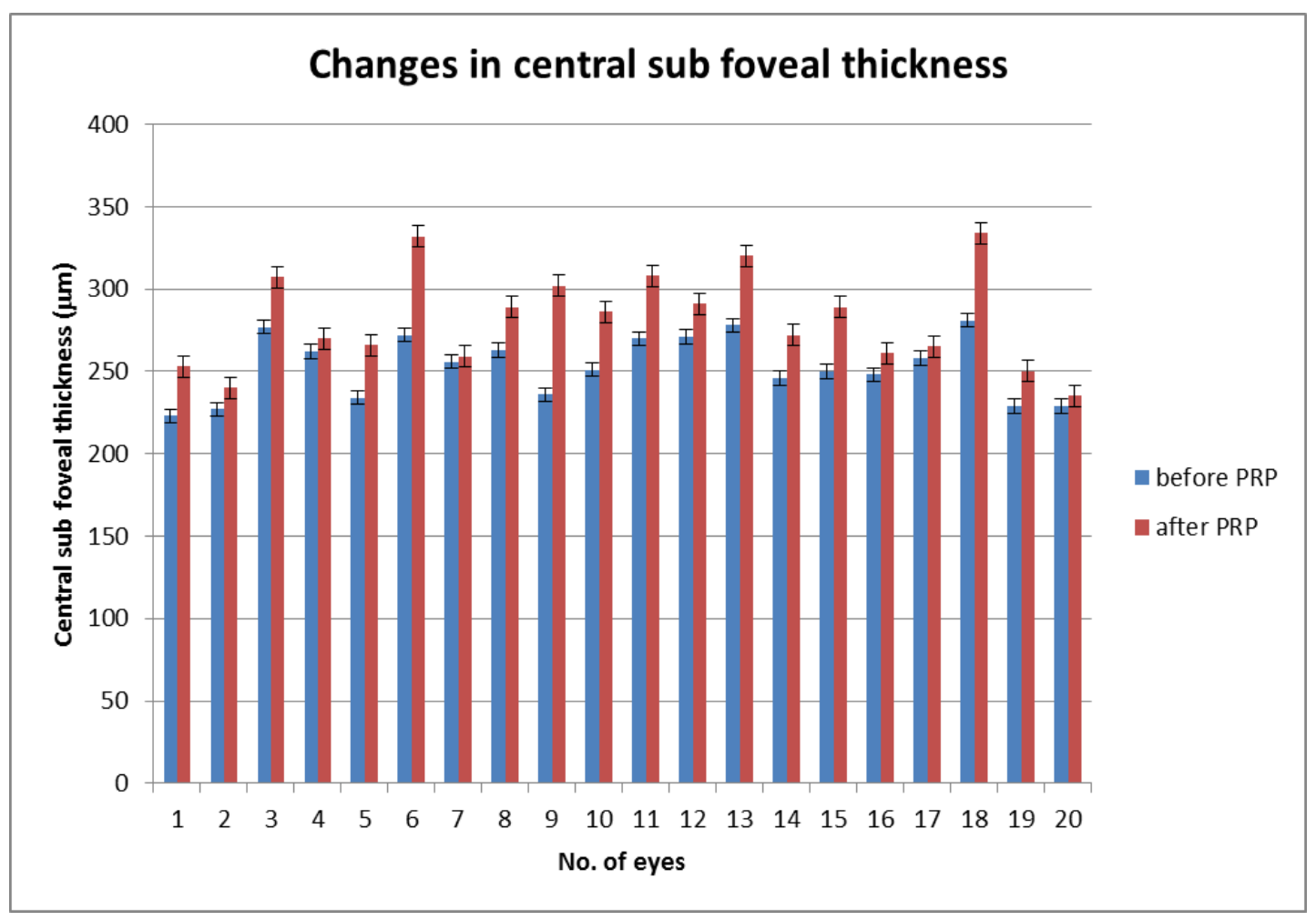

Fig.(2): Changes in central sub foveal thickness ( $\square \mathrm{m})$ before and after 3 months' PRP

Table (1): Complications distribution of the study group

\begin{tabular}{|c|c|}
\hline Complications & Total $(\mathbf{n = 2 0})$ \\
\hline No complication & $\mathbf{5 ( 2 5 \% )}$ \\
\hline Positive complications & $\mathbf{1 5}(\mathbf{7 5 \%})$ \\
\hline Cystoid macular edema & $6(30 \%)$ \\
\hline Diffuse macular edema & $4(20 \%)$ \\
\hline Posterior vitreous detachment (PVD) & $2(10 \%)$ \\
\hline Neurosensory detachment & $2(10 \%)$ \\
\hline Epiretinal membrane (ERM) & $1(5 \%)$ \\
\hline
\end{tabular}

Table (2): Panretinal photocoagulation's description of the study group

\begin{tabular}{|c|c|c|}
\hline Panretinal Photocoagulation & Range & Mean \pm SD \\
\hline No. of Shots & $1800-2250$ & $2021.00 \pm 174.77$ \\
\hline Power & $450-650$ & $540 \pm 61.98$ \\
\hline
\end{tabular}

\section{DISCUSSION}

In our study, we evaluated the effect of conventional PRP on central subfoveal thickness and BCVA in patients with newly diagnosed PDR without clinically significant macular edema as confirmed by OCT.

The mean age was $59.00 \pm 9.93$ years (range, 33-72 years), with 8 patients $(53.3 \%)$ older than 60th and seven younger $(46.7 \%)$. 
The Wisconsin Epidemiological Study of Diabetic Retinopathy also found that the severity of diabetic retinopathy and clinically significant macular edema is not related to age, but is related to duration of diabetes. Gender and duration of diabetes were not significant influencing factors with respect to final visual outcome. These observations indicate that the final visual acuity is governed by laser treatment and any change in macular thickness. In our study, 15 eyes $(75 \%)$ of patients had stable or improved vision, while $25 \%$ had worse vision 3 months after PRP which was comparable to McDonald et al. (1985) when reported that $25 \%$ of eyes treated with PRP lost $\geq 2$ lines after a mean follow-up of 15 months. Also the Diabetic Retinopathy Study reported $10 \%$ of eyes with visual loss after PRP. Overall, $25 \%-43 \%$ of eyes have been reported to have visual loss or changes after PRP in various studies (Khan et al., 2014).

Shimura et al. (2005) reported that in eyes with PDR and without clinically significant macular edema, PRP did not affect postoperative vision in $85 \%$ of eyes, which is also close to the findings of our study $(75 \%)$. PRP inducing visual loss in these eyes was less common, accounting for $15 \%$ of eyes, $(25 \%)$ in our study. Thus, eyes with PDR and without clinically significant macular edema generally tolerate the insult to the bloodretinal barrier during PRP reasonably well (Soman et al., 2012).

In our study, there was a statistically significant increase in central subfoveal thickness after 3 months follow-up, while BCVA returned close to baseline at the same follow-up visit.
In our study, 6 eyes $(30 \%)$ developed cystoid macular edema, 4 eyes (20\%) diffuse edema, but none developed tractional retinal detachment or neovascular glaucoma. Those developed vitreous hemorrhages before completion of PRP were excluded from our study.

Defective vision following PRP was also studied by McDonald et al. (1985), who found that the main causes were macu $\neg$ lar edema (32\%) followed by vitreous hemorrhage (23\%), tractional retinal detachment (14\%), epiretinal membrane $(9 \%)$, macular ischemia $(7 \%)$, cataract, and neovascular glaucoma (5\%) (Soman et al., 2012).

Even though $25 \%$ of patients had visual loss by the end of 3 months of follow-up, mean vision in this group did not decrease significantly from baseline.

In our study, the mean pretreatment central subfoveal thickness was 253.05 $\mu \mathrm{m}$, which increased during follow-up and remained higher at $281.45 \mu \mathrm{m}$ (an $89.9 \%$ increase) by 3 months follow-up. Mean central foveal thickness at final follow-up remained high, although the mean visual acuity had normalized by the end of 3 months of follow-up. Similar observations were reported by Shimura et al. (2003) in eyes that underwent PRP sessions on a weekly basis than those who underwent PRP biweekly. They found that visual acuity was unaltered in spite of a $142 \%$ increase in mean foveal thickness, and the type of macular edema seen on OCT appeared to be more relevant and better correlated with visual outcome than the quantitative estimation of foveal thickness (Soman et al., 2012).

In our study, eyes with cystoid macular edema had a worse visual outcome than 
those with diffuse edema. These eyes may require additional therapy, as observed by some authors who have found that even in eyes with PDR undergoing PRP, posterior sub-Tenon's steroid injection has beneficial effects for preventing PRPinduced foveal thickening and visual dysfunction.

In the Manchester Pascal Study, Muqit et al. (2010) conducted a randomized study comparing single spot, $100 \mathrm{~ms}$, multisession PRP with a multi spot, $20 \mathrm{~ms}$ single session PRP. In their cohort, 19 eyes received multi spot, $20 \mathrm{~ms}$, single session PRP. These patients developed a statistically insignificant $2 \mu \mathrm{m}$ increase in central subfoveal thickness at 4 -week post treatment, with a statistically insignificant $2 \mu \mathrm{m}$ decrease at 12-week post treatment.

Chappelow et al. (2012) retrospectively studied 82 eyes with newly diagnosed, high-risk PDR who had at least 6 months of follow-up. They reported that eyes treated with multi spot, 20ms PRP exhibited a higher treatment failure rate, defined as either persistence or recurrence of neovascularization, than conventional PRP when delivered as a comparable number of laser spots. They hypothesized that the higher laser fluence of conventional, 100ms PRP led to a larger area of heat diffusion and a larger area of coagulated retina following $100 \mathrm{~ms}$ conventional PRP, accounting for the difference in efficacy between these two laser parameters.

Other studies have also shown that higher numbers of laser spots are required for multi spot, 20ms PRP to obtain a similar total retinal treatment area as that seen with 100ms PRP (Salman, 2011).
Thus, foveal thickness estimation may not be an appropriate guide as to visual status. The Diabetic Retinopathy Clinical Research Network has reported that foveal thickness on OCT does not correlate with visual acuity, particularly in eyes with macular edema undergoing focal laser treatment, and even shows paradoxical responses.

Characteristics of macular edema correlate better with visual outcome, as was seen in their study, where presence of cystoid macular edema and epiretinal membrane resulted in poor visual outcome in this group of patients (Soman et al., 2012).

\section{CONCLUSION}

PRP is safe and effective in treating and preserving vision in PDR, although causing temporary drop in vision and changes in macular morphology/ thickness. This drop of vision can normalize by 3 months. Macular edema is the commonest cause of this drop in vision. Cystoid and diffuse macular edema had the greatest impact on vision. Eyes which lose vision due to macular edema may need alternative therapy in the form of intravitreal pharmacotherapy or additional laser sessions. This study also reaffirms the fact that central subfoveal thickness does not always influence the visual outcome and may show no correlation at all.

\section{REFERENCES}

1. Chandra, S., Sheth, J., Anantharaman, G. and Gopalakrishnan, M. (2018): Ranibizumab-induced retinal reperfusion and regression of neovascularization in diabetic retinopathy: An angiographic illustration. American Journal of Ophthalmology case reports, 9, 41-44. 
2. Chappelow A. V., Tan K., Waheed N. K. and Kaiser P. K. (2012): Panretinal photocoagulation for proliferative diabetic retinopathy: pattern scan laser versus argon laser. American Journal of Ophthalmology, 153:1:137.e2-142.e2.

3. Evans JR, Michelessi $M$ and Virgili G. (2014): Laser photocoagulation for proliferative diabetic retinopathy. Cochrane Database Systematic Rev, 11:Cd011234.

4. Khan P., Tiwari SP. and Pande S. (2014): Effect of Panretinal Photocoagulation on Visual Field and Macular Function in Diabetic Retinopathy.Sch. J. App. Med. Sci., 2(5F): 1946-1950.

5. Mukhtar A, Khan MS, Junejo M, Ishaq M and Akbar B. (2016): Effect of pan retinal photocoagulation on central macular thickness and visual acuity in proliferative diabetic retinopathy. Pakistan Journal of Medical Sciences, 32(1):221-224.

6. Muqit, M. M. K., Marcellino, G. R., Henson, D. B., Young, L. B., Patton, N., Charles, S. J. and Stanga, P. E. (2010): Single-session vs multiple-session pattern scanning laser panretinal photocoagulation in proliferative diabetic retinopathy: The Manchester Pascal study. Archives of Ophthalmology, 128(5): 525-533.

7. Nentwich MM and Ulbig MW. (2015): Diabetic retinopathy - ocular complications of diabetes mellitus. World J Diabetes, 6(3):489-499.
8. Pournaras, C. J., Pournaras, J.-A. and Mendrinos, E. (2012): Diabetic Macular Edema: Cases and Diagnostics. ESASO Course Series: 81-90.

9. Salman A.G (2011): Pascal laser versus conventional laser for treatment of diabetic retinopathy. Saudi Journal of Ophthalmology, 25:2: 175-179.

10. Shaw JE, Sicree RA and Zimmet PZ. (2010): Global estimates of the prevalence of diabetes for 2010 and 2030. Diabetes Res Clin Pract., 87(1):4-14.

11. Soman, M., Ganekal, S., Nair, U. and Nair, K. (2012): Effect of panretinal photocoagulation on macular morphology and thickness in eyes with proliferative diabetic retinopathy without clinically significant macular edema. Clinical ophthalmology (Auckland, N.Z.), 6: 20132017.

12. Wu, P.-C., Lai, C.-H., Chen, C.-L. and Kuo, C.-N. (2012): Optical Coherence Tomographic Patterns in Diabetic Macula Edema Can Predict the Effects of Intravitreal Bevacizumab Injection as Primary Treatment. Journal of Ocular Pharmacology and Therapeutics, 28(1): 59-64. 


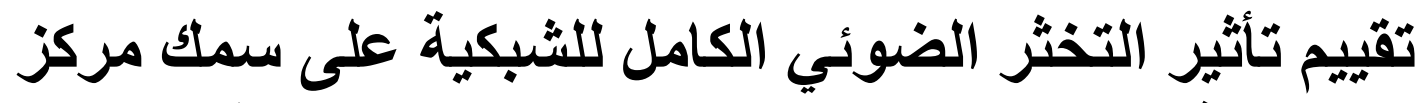

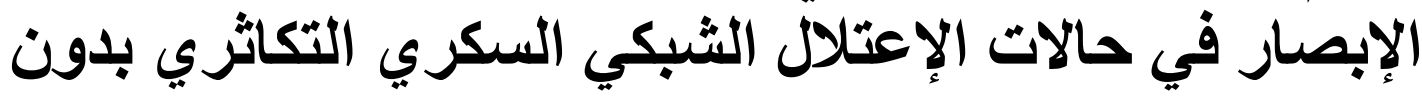

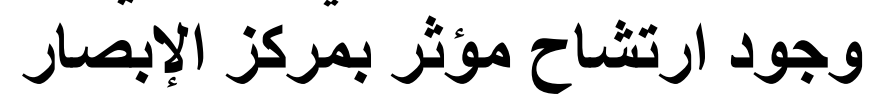

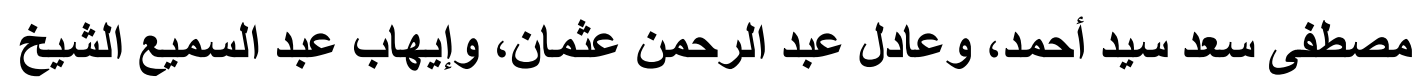
قسم طب وجراحة العيون، كلية الطب، جامعة الأزهر، القاهرة، مصر

خلفيــة البحــث: يُعــــ الاعــتلال الثــبكي الســكري التكــاثري مــن أخطــر مر احــل الاعــتلال

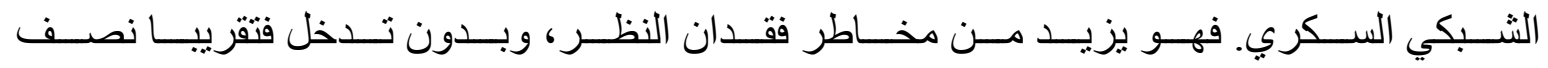

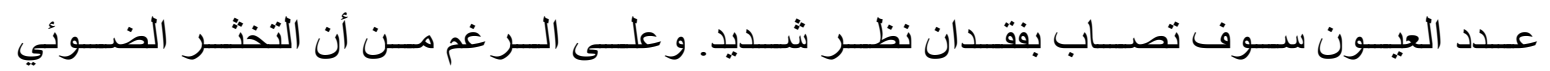

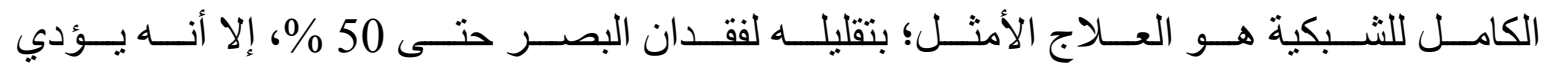

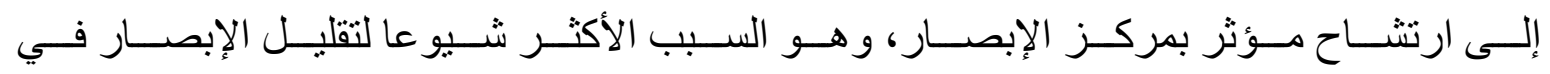

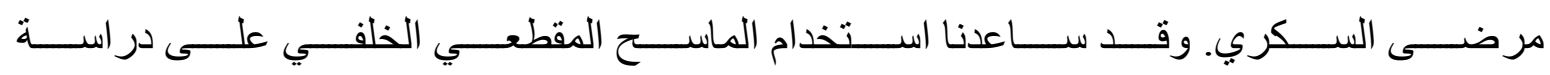
الارتشاحات السكرية على مركز الإبصار وخصائصها.

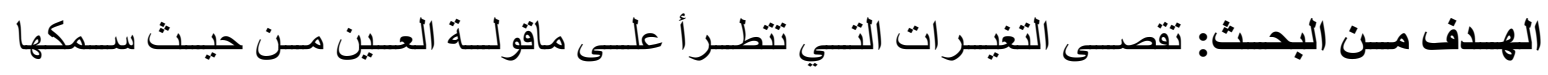

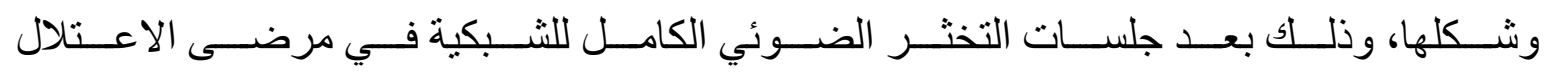

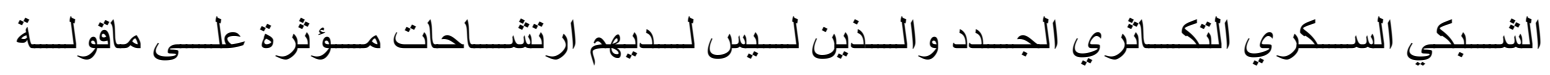
العين.

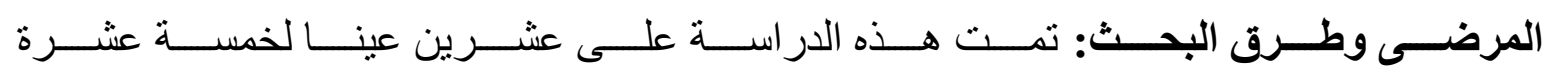

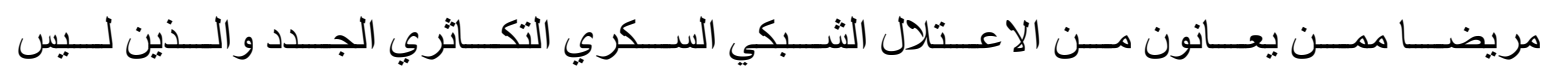

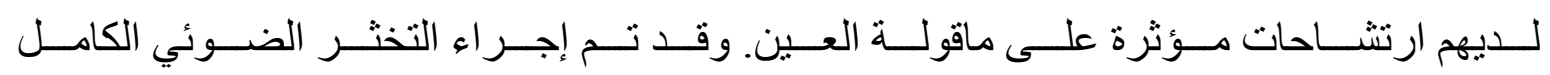
للثبكية على ثناث جلسات ، بفاصل أسبوع بين كل جلسة.

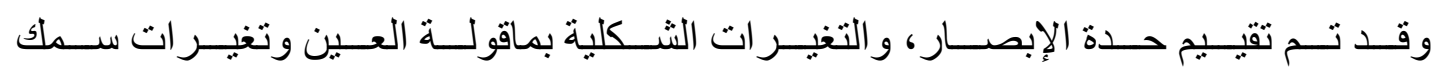

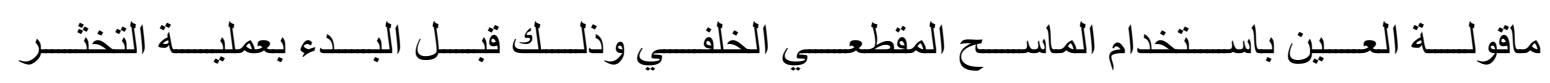
الضوئي الكامل للشبكية، وبعدها بثلاثة أثهر.

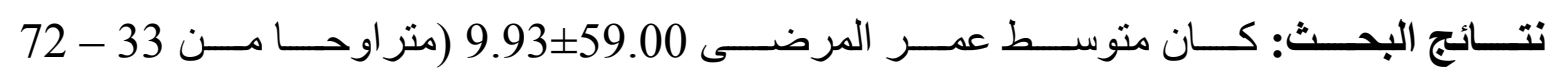

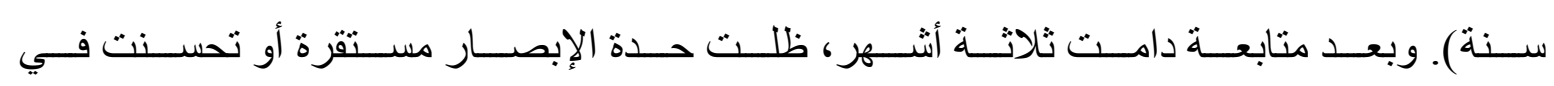




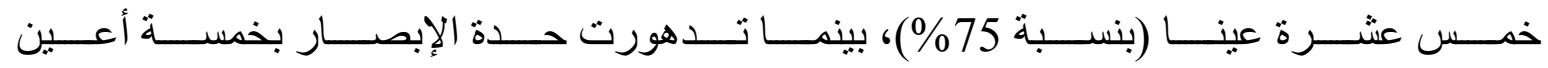

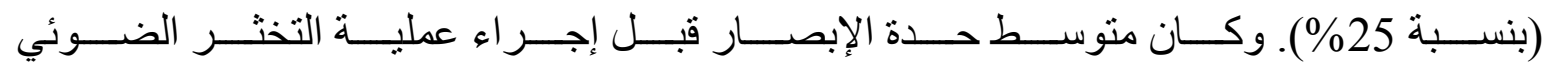

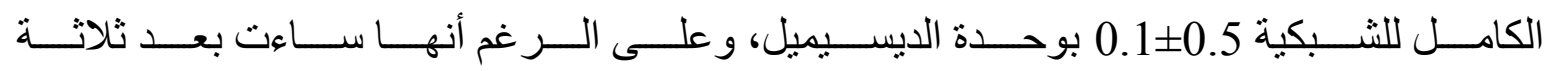

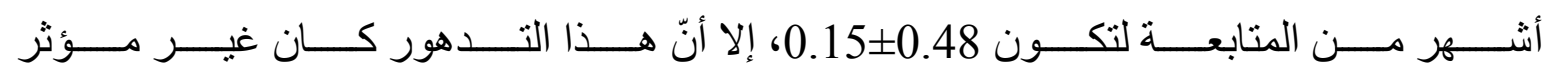
إحصائيا.

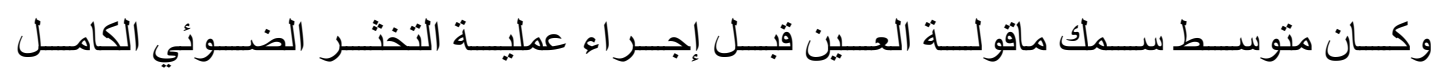

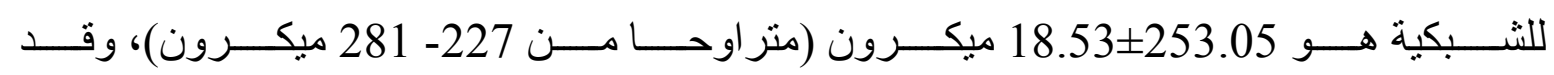

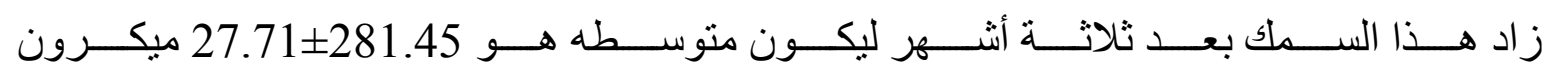
(متر اوحا من 240-344 ميكرون).

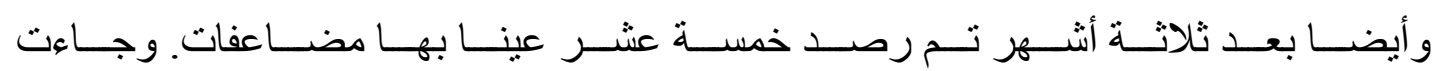

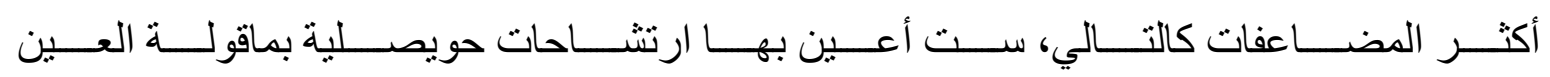

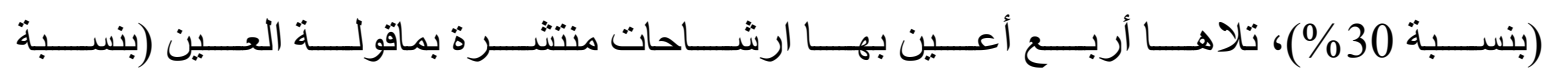

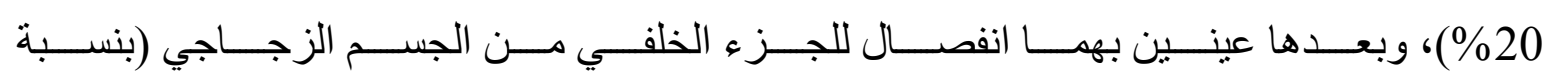

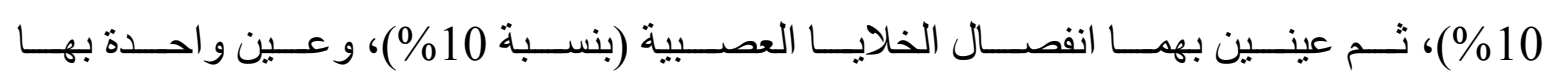
غثاء فوق شبكي (بنسبة 5\%).

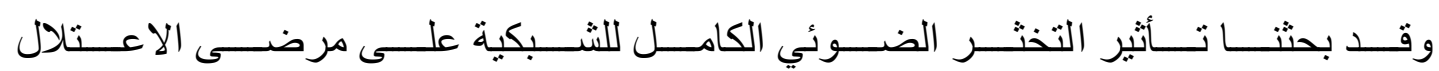

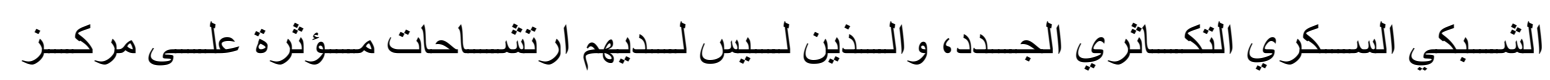

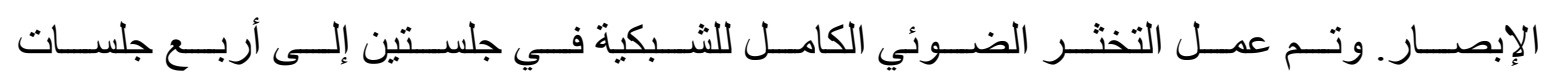
بفاصل أسبوع بين كل جلسة و الأخرى.

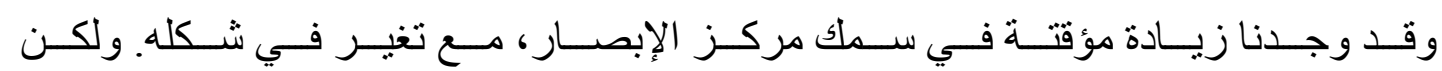

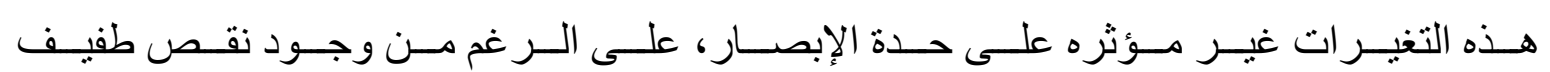
ومؤقت في الرؤية.

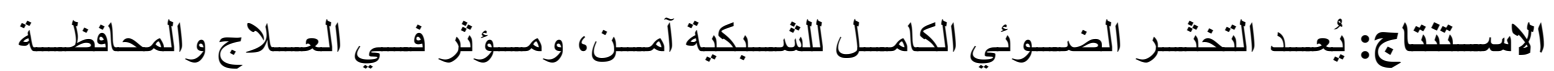

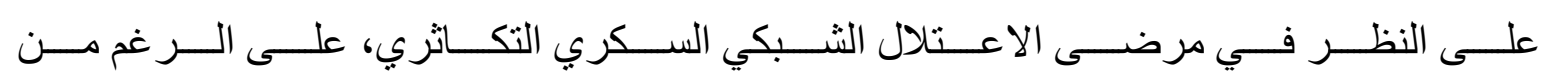

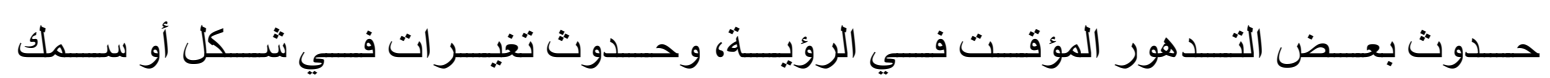

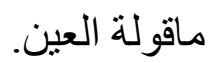

